\title{
Las guerras mundiales en sus contextos históricos
}

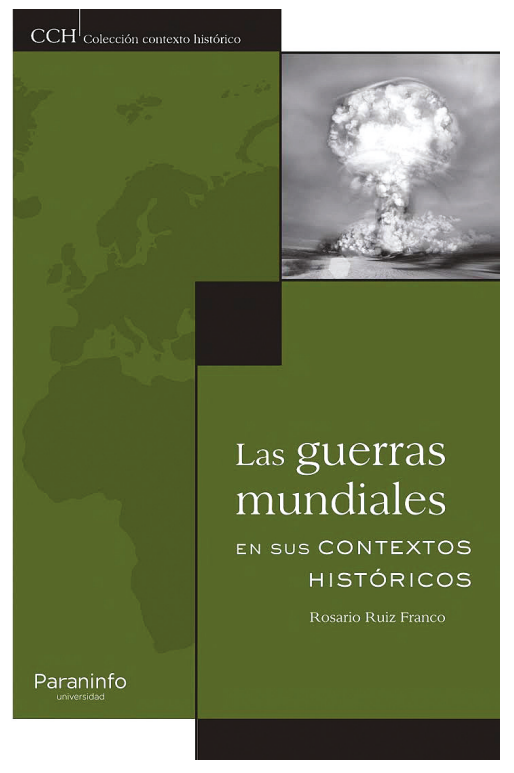

FICHA BIBLIOGRÁFICA

Rosario Ruiz Franco, Las guerras mundiales en sus contextos históricos, Madrid, Ediciones Paraninfo, colección Contexto Histórico, 2017, 200 págs, ISBN: 978-84-283-3836-3.

\section{Antonio Manuel Moral Roncal Universidad de Alcalá}

TRAS LA EDICIÓN DE UNA ABUNDANTE BIBLIOGRAFía sobre las guerras mundiales surgida en España con motivo del primer centenario de la Primera y del 70 aniversario del final de la Segunda, resultaba necesario un libro que realizara el ingente esfuerzo de resumir en dos centenares de páginas las principales aportaciones y conclusiones a las que habían llegado los grandes especialistas. De ahí la oportunidad de este volumen, firmado por la profesora Rosario Ruiz Franco, que sintetiza no sólo las grandes fases bélicas de los conflictos sino también 
el debate sobre las circunstancias que rodearon sus desencadenamientos y las consecuencias que tuvieron a corto plazo.

Como advierte la autora, la falta de consenso sobre sus causas (particularmente prefiero el término de "precedentes" o "circunstancias" pero la didáctica se impone) resulta ser un reflejo de los múltiples factores que pudieron motivar sus estallidos. Por ello, numerosos han sido los historiadores que han tenido que enfrentarse a las siguientes preguntas: si se debe reconocer el alcance de los condicionamientos externos e internos de larga duración ¿cuáles fueron los más decisivos?. Si se debe valorar las circunstancias inmediatas y las acciones de los dirigentes... ¿éstos fueron los factores determinantes? ¿O los conflictos armados fueron resultado de una amalgama de ambos?

Desde luego, la autora llega a la conclusión de la necesidad de explicar las circunstancias generales precedentes al estallido de ambas conflagraciones, de ahí su interés en acercar al lector a la Belle Époque o periodo de la Paz Armada, así como a las décadas de los años 20 y 30, imprescindibles para explicar la Segunda Guerra Mundial. Precisamente, en la inmediata posguerra mundial, se produjo un Encuentro franco-germano de historiadores en 1951, en cuyas conclusiones se argumentó que, en 1914, no había habido deseo premeditado de guerra europea en ningún gobierno. Sin embargo, esta tesis fue barrida -como se señala en el libro-por el alemán F. Fischer (autor de Objetivos de Alemania en la Primera Guerra Mundial, editado en 1961 y 1967), el cual defendió la idea de la culpabilidad alemana, debido a su política de expansión para dominar Europa y apuntalar el II Reich, planificando una guerra de forma deliberada. La influencia de sus tesis produjo un gran debate en la segunda mitad del siglo XX, pues pronto acudieron a su senda otros historiadores que afianzaron esa idea de responsabilidad única. I. Geiss analizó la importancia de la Weltpolitik de Guillermo II, mientras J. Röhl sobrevaloraba los planes militares alemanes preexistentes en julio de 1914, olvidando que todas las grandes potencias tenían uno. J. Kocka, A. Meyer, S. Van Evera publicaron sendos estudios sobre grupos sociales elevados que demostraron, en su opinión, su apoyo a políticas agresivas en el exterior, cuyo objetivo real era contener reformas democráticas e impedir la revolución en Alemania, apuntalando de esa manera la teoría de responsabilidad unívoca en el estallido de la Gran Guerra, al igual que nadie debatía la de la Alemania del III Reich en la Segunda.

Sin embargo, pronto también empezaron a surgir detractores de la escuela de Fisher, como R. Evans, G. Eley y D. Blackbourn que negaron la supuesta influencia de los factores internos del Reich en su política exterior, así como Lieven, Steiner y Kieger que lo minimizaron igualmente en las desarrolladas por otras potencias europeas. Varios investigadores, como A. Taylor, valoraron el cálculo equivocado británico en su política exterior desarrollada entre 1900 y 1914 para responder a sus primeros signos de decadencia, descolonización y eclipse económico. G. Ritter subrayó el manejo deficiente de la crisis por los políticos europeos, excesivamente influidos por el optimismo militar, de tal manera que fue surgiendo cada vez más estudios que apoyaron la tesis de la responsabilidad compartida para explicar 1914.

De manera paralela, si bien resulta imposible negar la iniciativa alemana en la invasión de Polonia en 1939, la comunidad de historiadores ha subrayado, en los últimos tiempos, la necesidad de valorar el papel de la Unión Soviética, Gran Bretaña y Francia en los años 30, así como su vacilante y contradictoria política exterior antifascista, como ha analizado, reciente- 
mente, Michael Seidman en su libro Antifascismos (2017). Así como el complejo entramado diplomático y político en las relaciones entre Japón y las potencias occidentales en esa misma década. Todo ello aparece, de forma resumida, en este volumen, que incorpora también el papel de los países neutrales -especialmente España- en ambas guerras.

Al final del cuerpo central del libro, acentuando su carácter didáctico, se presenta un adecuado conjunto de mapas sobre el escenario bélico europeo, lamentando en este sentido la falta de, al menos, uno sobre la guerra del Pacífico, ya que, durante la Segunda Guerra Mundial, los Aliados y el Imperio japonés sostuvieron un decisivo enfrentamiento en esa parte de globo. A continuación, la autora nos muestra una imprescindible lista de libros y artículos que ha consultado para la elaboración del libro, plenamente actualizada. Y como el cine fue un medio de propaganda fundamental en las guerras $y$, más tarde, de perpetuación visual de las mismas hasta nuestros días, la autora ha tenido el acierto de recoger al final de libro una selección de los títulos más destacados, donde se aprecia la hegemonía de filmes ambientados en la Segunda más que en la Primera Guerra Mundial.

Si el objetivo fundamental de Las guerras mundiales en sus contextos históricos ha sido aportar una visión contextualizada de los dos grandes episodios bélicos en sus ámbitos cronológicos, procurando un equilibrio entre los aspectos militares y políticos más conocidos, las dimensiones sociales, económicas y psicológicas de ambos acontecimientos, el lector concluye que se ha cumplido ampliamente con el mismo. 